ECCOMAS

Proceedia

\title{
ANALYTICAL INVESTIGATION OF THE TENSILE EXPERIMENTS MODELING THE ELONGATION DEGREE OF R/C WALLS FOR STUDYING THE LATERAL BUCKLING PHENOMENON
}

\author{
Theodoros A. Chrysanidis ${ }^{1}$, Vassilis P. Panoskaltsis ${ }^{1}$ \\ ${ }^{1}$ Demokritos University of Thrace \\ University Campus Xanthi-Kimmeria, P.C. 67100, Xanthi, Greece \\ theodoros_gr@yahoo.com,vpanoska@civil.duth.gr
}

\begin{abstract}
In the context of the present work, the influence of the degree of tension on the phenomenon of transverse instability of reinforced concrete walls is examined. The present investigation is basically analytical but it contains experimental results of 4 test specimens published from the first author in the past. These specimens simulate the extreme boundary edges of structural walls. All columns simulate only the extreme reinforced areas of the walls, in order to study the basic mechanism of the phenomenon. The detailing of the specimens consists of 4 rebars with a diameter of $8 \mathrm{~mm}$ for each bar. The geometric dimensions are the same for all specimens. What differentiates the specimens from each other is the degree of tension they have sustained. More specifically, the tensile degrees used are 10\%o, 20\%, 30\%o, 50\%o. The loading stages of each specimen for all specimens are as follows: (a) Uniaxial central tensile loading on each test specimen, (b) Uniaxial central compression loading on each specimen till its failure due to buckling or due to an excess of its cross-section compressive strength. The present study focuses on the tensile loading stage only. Extreme tensile strains are also used, e.g., 30\% and 50\%, to take into account the cases of extreme seismic excitations. First, the experimental results from a previous publication are presented and afterwards they are followed by the numerical investigation of these 4 specimens using appropriate finite element software. Useful conclusions are drawn regarding the precision of the experimental tests investigating the influence of the degree of elongation on the phenomenon of transverse buckling. These conclusions are substantiated both experimentally and analytically, as the results of the tensile experiments are compared with the corresponding results of the analytical investigation.
\end{abstract}

Keywords: Degree of elongation, Lateral buckling, Structural walls, Tensile loading 


\section{INTRODUCTION}

Structural behavior and soil-structure interaction has troubled engineers worldwide for various types of structures [1]-[10]. Structural walls play an important role in the structures' behavior and safety against horizontal loads and especially against earthquake cyclic loading [11], [12]. It is well-known that the vast part of seismic loading is resisted by seismic walls in reinforced concrete structures [13]-[26]. One critical mode of failure which can appear during earthquake cyclic loading is the out-of-plane buckling of R/C shear walls [27]-[36]. It has been observed that such type of failure is so critical that can lead to partial or total collapses of multi-storey reinforced concrete buildings [37]. This phenomenon can appear when the boundary edges of seismic walls have sustained a large size of tensile loading during the first semi-cycle of seismic loading and then are subjected to a compressive loading during the second semi-cycle of earthquake loading [38]-[41]. Transverse buckling appears when the cracks formed during the first stage of tensile loading have such a large width that makes it impossible to be closed during the second stage of compressive loading [42]-[51]. The fact that the cracks cannot close when compression loading is applied leads to the wall buckling transverse to its plane. This phenomenon is called in international bibliography lateral buckling or transverse buckling or out-of-plane buckling and sometimes instead of using the word "buckling", the word "instability" is preferred.

The present study uses experimental tests performed in the past by the first author trying to investigate the mechanical parameters affecting the transverse instability [28]. These specimens were subjected to tensile strain equal to $10 \%, 20 \%, 30 \%$ and $50 \%$. In the framework of the present work, the four specimens subjected to tensile loading are modelled using finite element software and the results of this analytical investigation are compared to the existing experimental results concerning the tensile loading stage. It is noted that the experiments have taken place in the Laboratory of Strength of Materials of Aristotle University of Thessaloniki and the analysis of the results has taken place in Demokritos University of Thrace.

\section{EXPERIMENTAL RESEARCH}

\subsection{Test specimen characteristics}

The experimental investigation for the four test specimens has been described in detail by the first author in the past [28]. Figure 1a shows the geometrical characteristics of the four test specimens, while Figure $1 \mathrm{~b}$ displays the load test setup used for the application of the tensile loading. It is noted the fact that the tensile loading is the first stage of the two loading stages. In the framework of the present study, only the experimental results of the tensile loading stage are compared to the analytical ones. Table 1 shows the test specimens' characteristics.

\begin{tabular}{|c|c|c|c|c|c|c|}
\hline N/A & Specimen & $\begin{array}{c}\text { Dimensions } \\
(\mathrm{cm})\end{array}$ & $\begin{array}{c}\text { Longitudinal } \\
\text { reinforcement }\end{array}$ & $\begin{array}{c}\text { Transverse } \\
\text { reinforcement }\end{array}$ & $\begin{array}{c}\text { Longitudinal } \\
\text { reinforcement ratio } \\
(\%)\end{array}$ & $\begin{array}{c}\text { Degree of } \\
\text { elongation } \\
(\%)\end{array}$ \\
\hline 1 & L-10 & $15 \times 7.5 \times 76$ & $4 \times D 8$ & D4.2@33 mm & 1.79 & 10.00 \\
\hline 2 & L-20 & $15 \times 7.5 \times 76$ & $4 \times D 8$ & D4.2@33 mm & 1.79 & 20.00 \\
\hline 3 & L-30 & $15 \times 7.5 \times 76$ & $4 \times D 8$ & D4.2@33 mm & 1.79 & 30.00 \\
\hline 4 & L-50 & $15 \times 7.5 \times 76$ & $4 \times D 8$ & D4.2@33 mm & 1.79 & 50.00 \\
\hline
\end{tabular}

Table 1: Dimensions of the test specimens. 


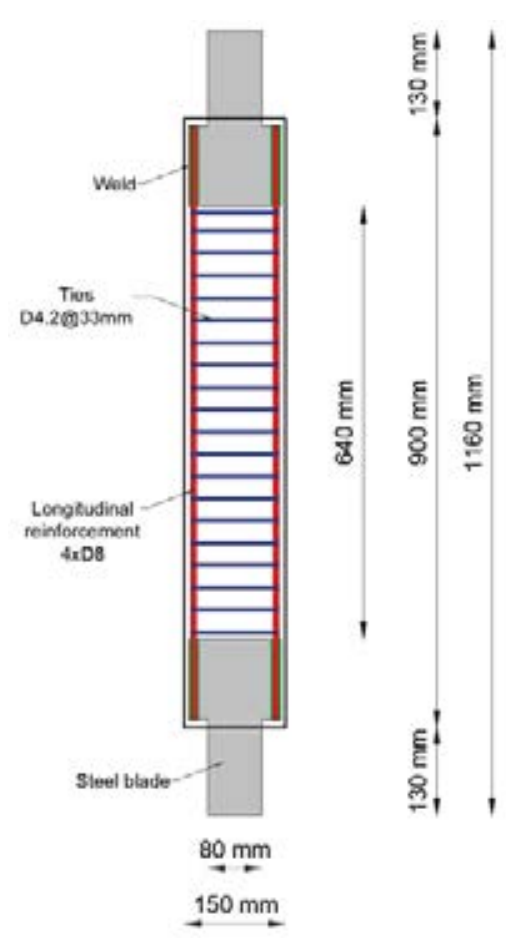

(a)

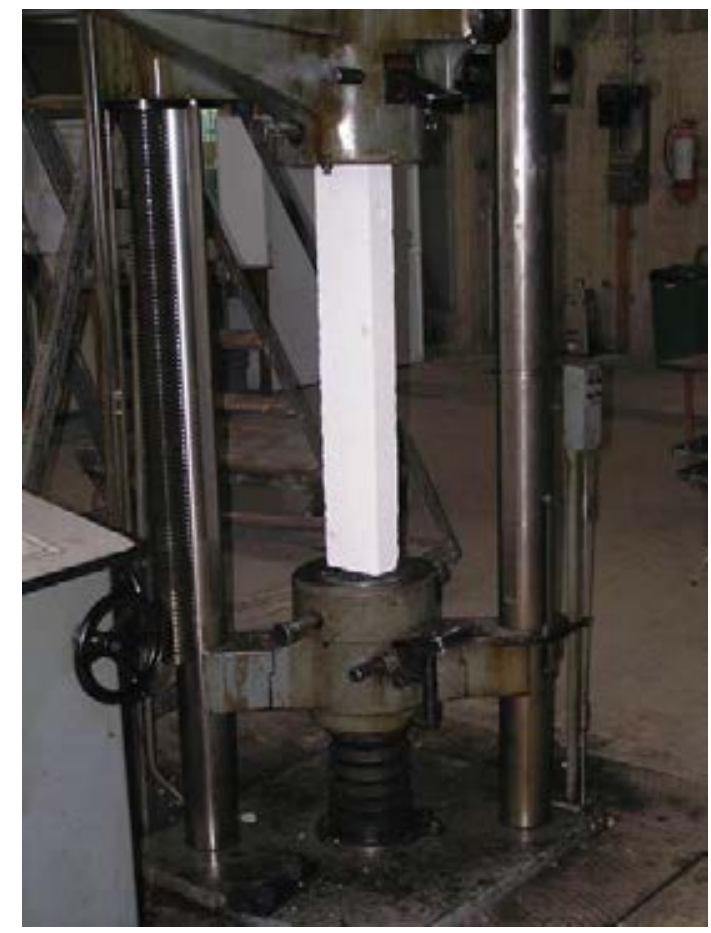

(b)

Figure 1: (a) Vertical reinforcement layout, (b) Test setup for tensile loading.

\subsection{Materials}

For all test specimens, materials used for their construction and their characteristics were also described by the first author in the past [28]. Table 2 displays the concrete resistance for all test specimens at 28 days and at the day that the compression test has taken place while Table 3 shows the mechanical properties for the longitudinal steel and the transverse ties.

\begin{tabular}{|c|c|c|c|c|}
\hline N/A & Specimen & $\begin{array}{c}\text { Concrete cube resistance } \\
(28 \text { days }) \\
(\mathrm{MPa})\end{array}$ & $\begin{array}{c}\text { Concrete cube resistance } \\
\text { (Compression test day) } \\
(\mathrm{MPa})\end{array}$ & $\begin{array}{c}\text { Concrete cylinder resistance } \\
\text { (Compression test day) } \\
(\mathrm{MPa})\end{array}$ \\
\hline 1 & L-10 & 24.89 & 28.00 & 23.00 \\
\hline 2 & L-20 & 24.89 & 28.00 & 23.00 \\
\hline 3 & L-30 & 23.33 & 25.56 & 20.56 \\
\hline 4 & L-50 & 24.89 & 28.00 & 23.00 \\
\hline
\end{tabular}

Table 2: Concrete mechanical properties.

\begin{tabular}{|c|c|c|}
\hline Reinforcement & $\begin{array}{c}\text { Yield strength } \\
(\mathrm{MPa})\end{array}$ & $\begin{array}{c}\text { Ultimate strength } \\
(\mathrm{MPa})\end{array}$ \\
\hline D8 (Longitudinal reinforcement) & 603.77 & 743.10 \\
\hline D4.2 (Transverse ties) & 552.02 & 670.91 \\
\hline
\end{tabular}

Table 3: Reinforcement mechanical properties. 


\subsection{Experimental results}

Each one of the four test specimens has been subjected to a different degree of elongation according to Table 1 and the results published by the first author in the past [28]. Figure 2 displays the shape of test specimens after the uniaxial tensile test has taken place. It is obvious that several cracks of different width have formed after the tensile loading according to the degree of elongation applied to each specimen.

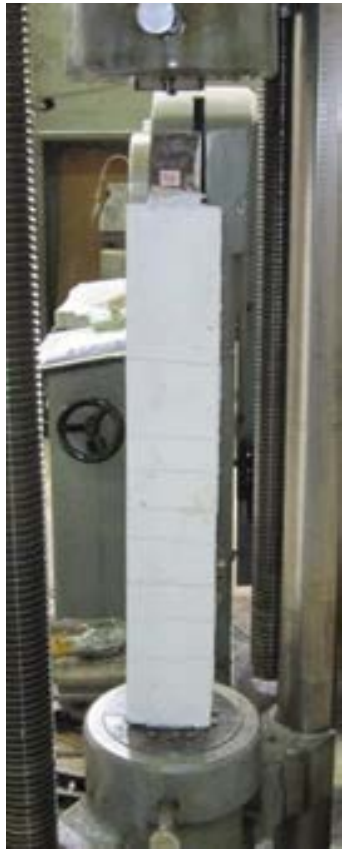

(a)

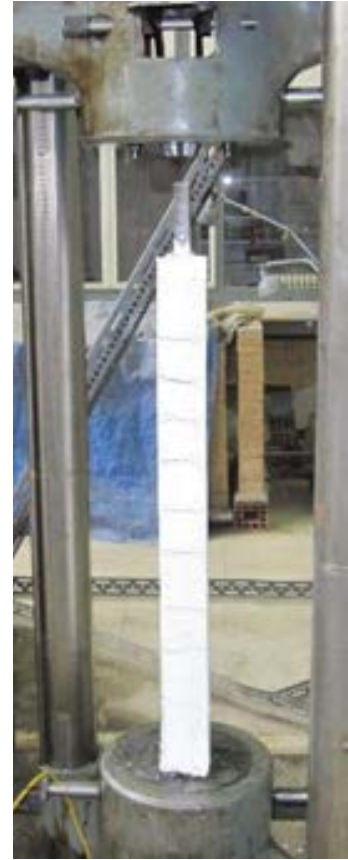

(b)

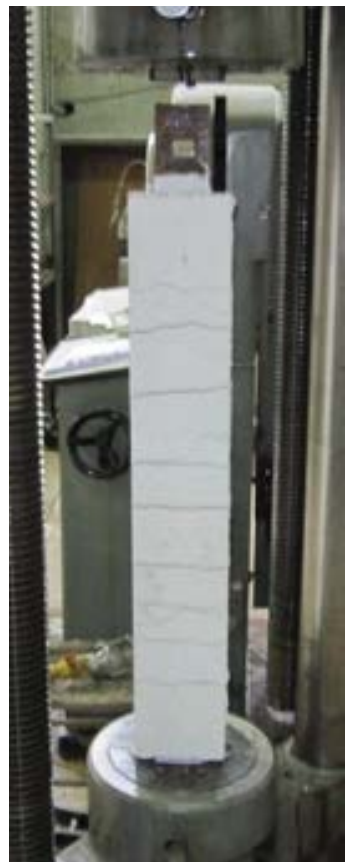

(c)

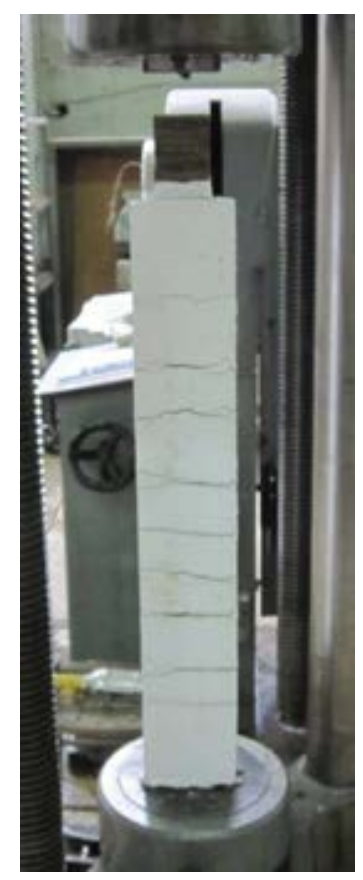

(d)

Figure 2: Specimens with low reinforcement ratio after the uniaxial tensile test: (a) L-10, (b) L-20, (c) L-30, (d) L-50

\section{ANALYTICAL RESEARCH}

\subsection{Modeling of test specimens}

The analytical research has taken place using a finite element software. 3D elements were used in this software to model all four test specimens subjected to tensile loading. It is noted, as it has been said before, that the present work focuses on modeling only the first stage of loading; meaning the tensile loading path till certain preselected and different degrees of elongation. For the concrete material, the inelastic concrete model found in the software library of isotropic plasticity has been chosen. For the reinforcement bar material, the properties derived from experiments are inserted in the software to model the inelastic behaviour of reinforcement steel. A bilinear isotropic model has been chosen for the behaviour of rebar steel. The same inelastic model has been selected to model the behaviour of the steel used for the transverse ties. This model is again the bilinear isotropic model. 3D finite elements having an edge of $2 \mathrm{~cm}$ are used for the modeling of the concrete column section. Both the longitudinal reinforcement and the transverse ties are modeled using 3D finite elements having a length equal to $1 \mathrm{~cm}$. Figure 3 shows the 3D model of the column either for the whole column section or the reinforcement steel only. The column model is considered fixed at its base. 


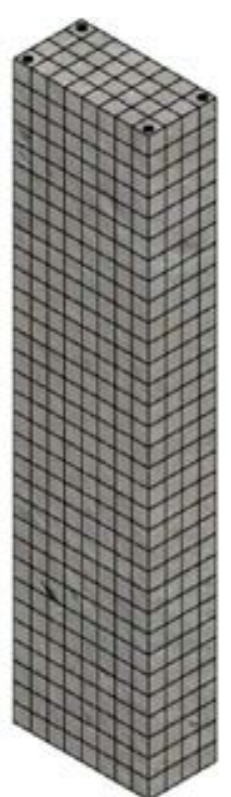

(a)

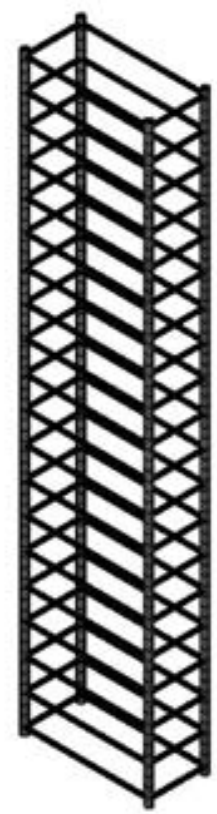

(b)

Figure 3: (a) 3D model for column, (b) 3D model for the column reinforcement.

\subsection{Analytical results}

Figure 4 displays the displacement along the column height after the end of the tensile loading test for all four test specimens. The displacement is zero at the fixed column base.

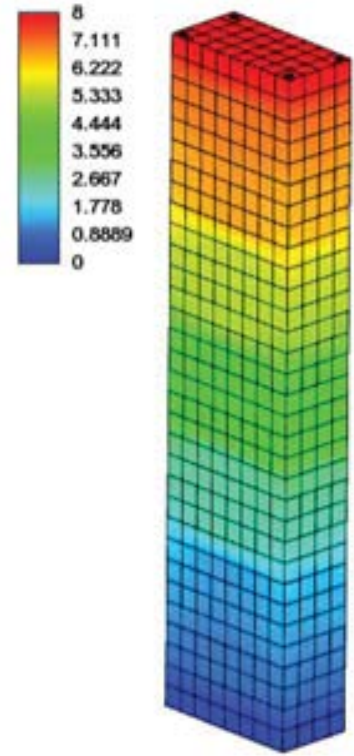

(a)
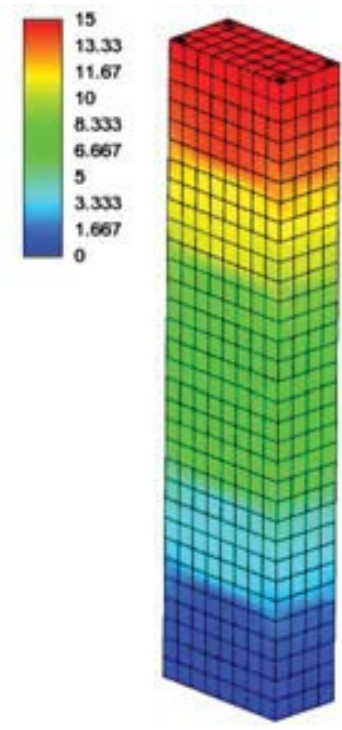

(b)
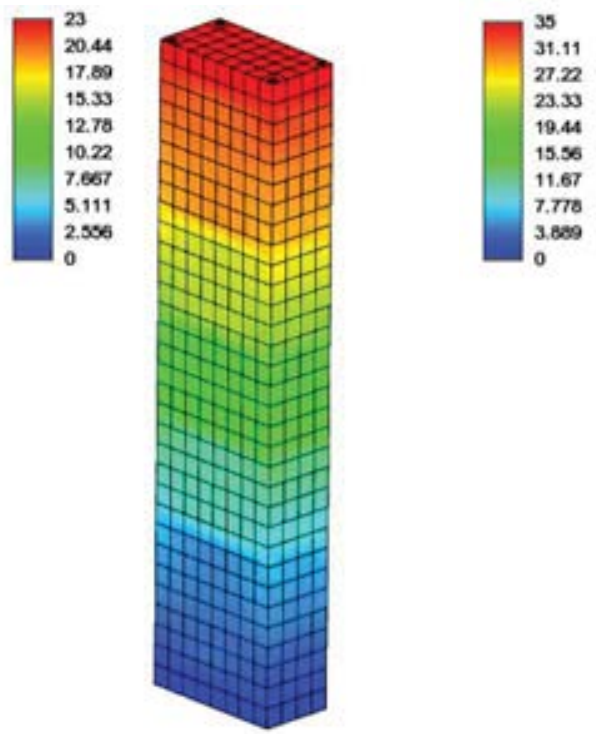

(c)

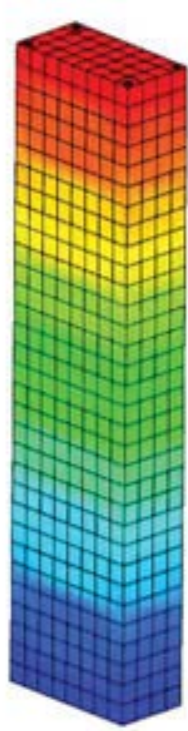

(d)

Figure 4: Displacement along the column axis at the end of the tensile test: (a) L-10, (b) L-20, (c) L-30, (d) L-50 


\section{ANALYSIS OF RESULTS}

\subsection{Analytical versus experimental results}

A comparison takes place between the load versus elongation diagrams which have resulted from the experimental tensile tests and the tests applied to the analytical models of the four specimens modeling the boundary edges of seismic walls (Figures 5-8).

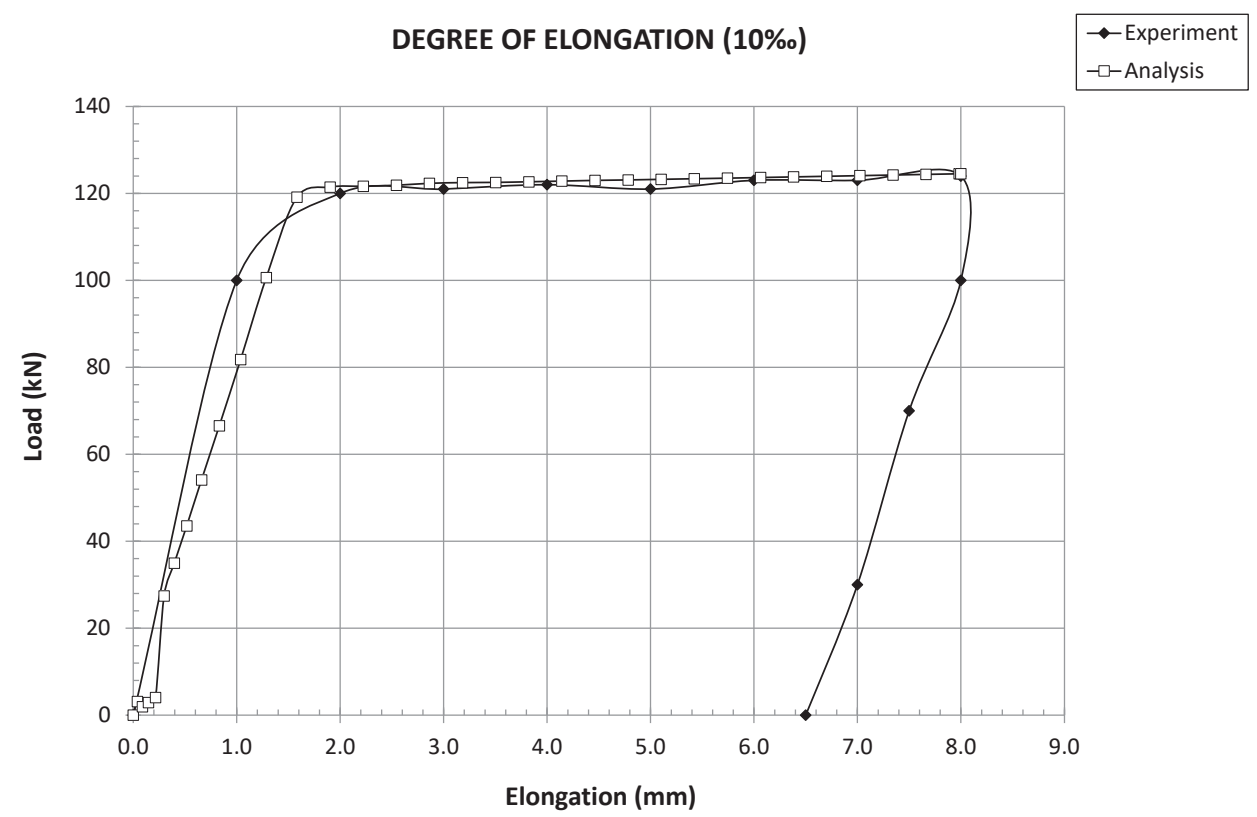

Figure 5: Load versus elongation diagram for specimen L-10.

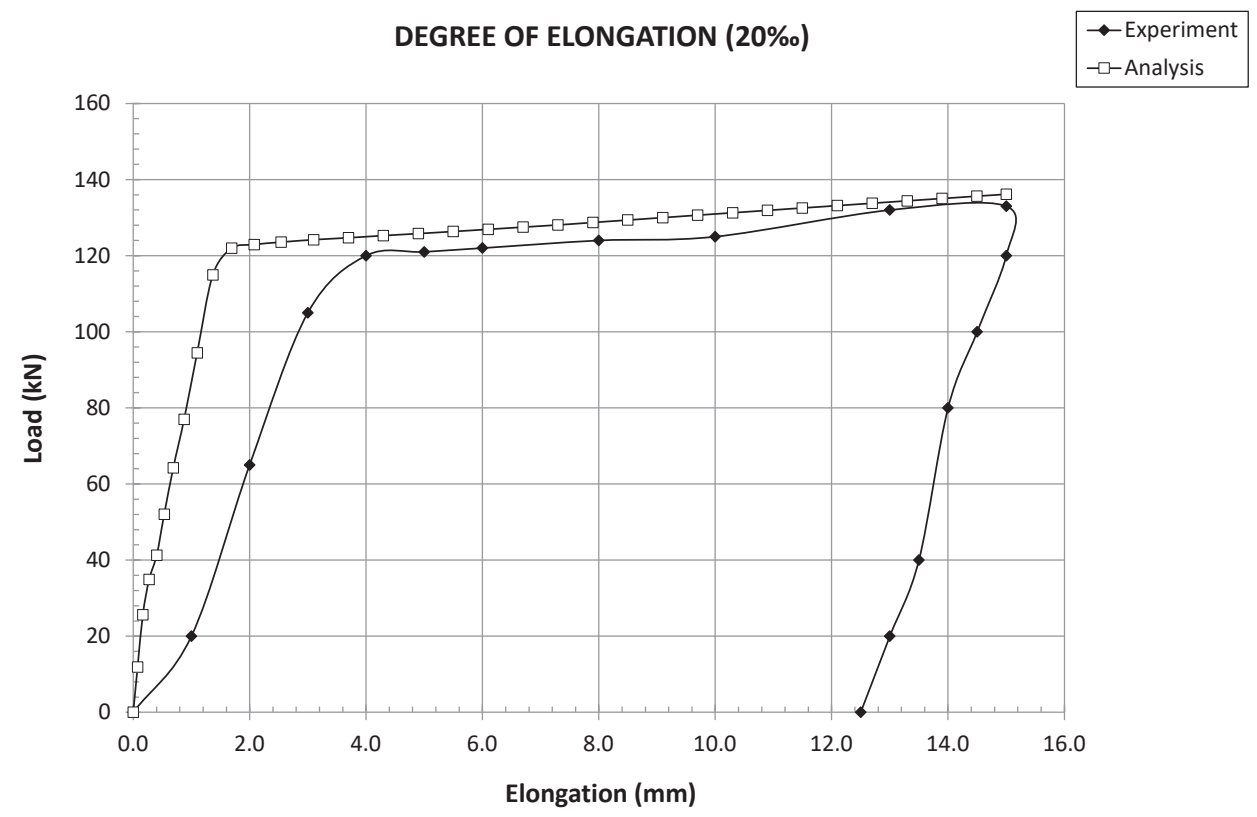

Figure 6: Load versus elongation diagram for specimen L-20. 


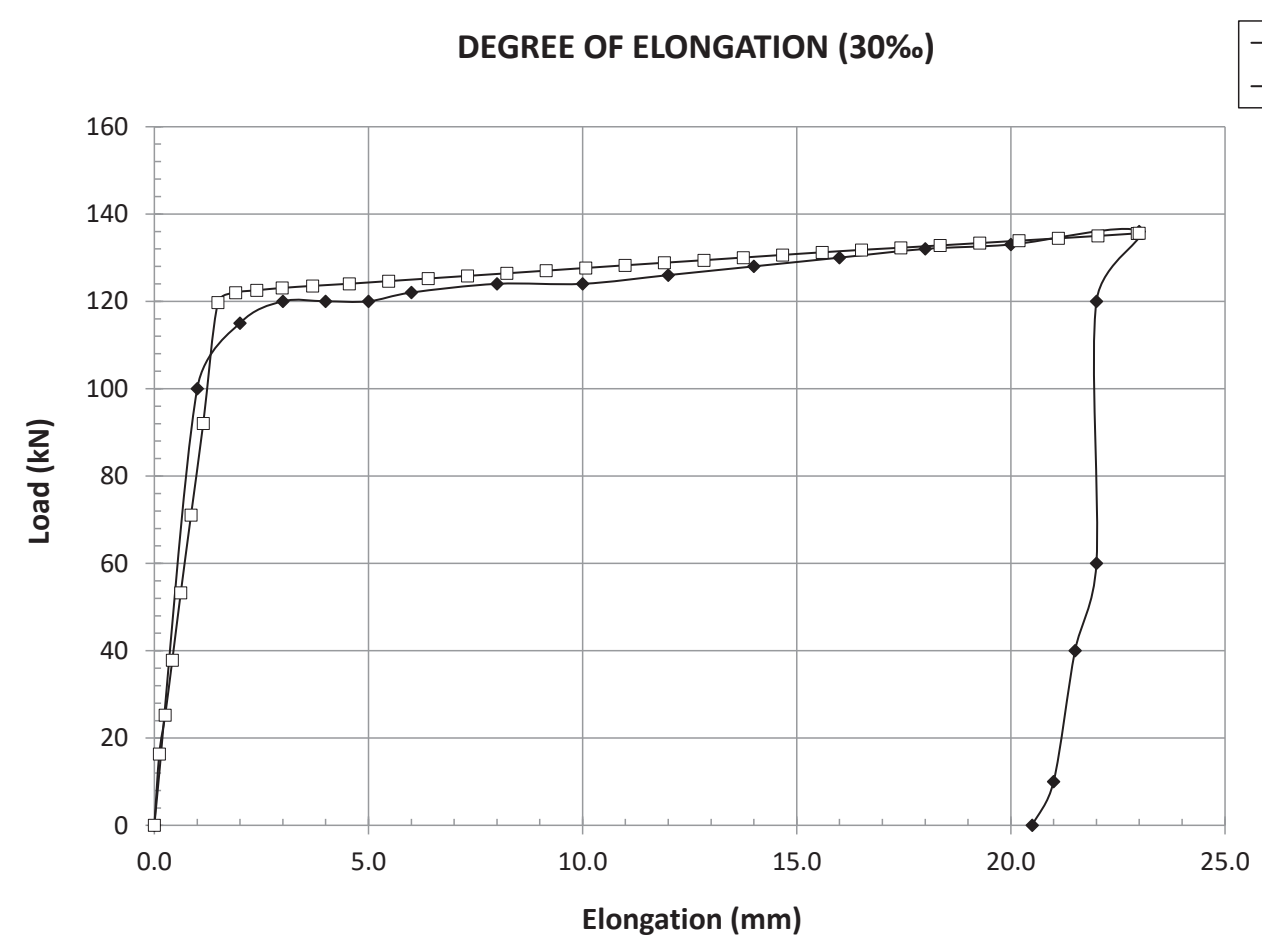

Figure 7: Load versus elongation diagram for specimen L-30.

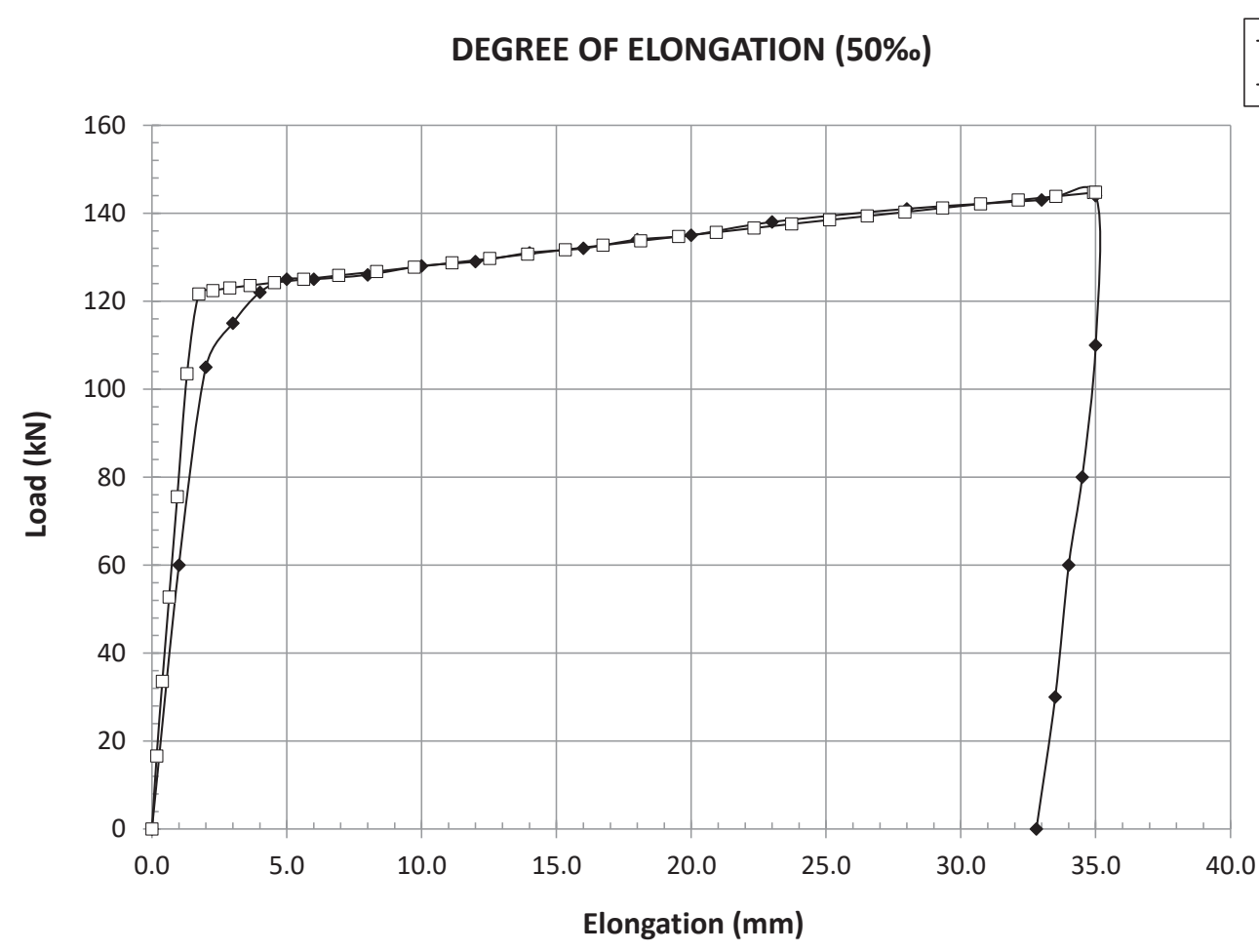

Figure 8: Load versus elongation diagram for specimen L-50. 


\subsection{Analysis of results}

The analysis of the previous results leads to the following:

1. Figure 4 displays the displacement along the vertical axis which is the Z-axis and coincides with the height of the prism specimens modeling the boundary edges of structural walls. It can be seen that each specimen is strained till the preselected displacement according to the preselected degree of elongation.

2. The vertical displacement is zero at the base of the prisms since the base is rigid (Figure 4). The maximum vertical displacement is found towards the upper part of the specimens where the tensile load is applied. The same phenomenon takes place in the tensile experiments where the tensile load is applied at the upper part of the test specimens while at the bottom part the test specimens are held rigidly by the grapples of the tensile machine.

3. It is obvious that there is an almost perfect correlation between the experimental and the analytical results for all test specimens (Figures 5-8). The elastic branch is the same both in the experiments and the analysis. The same thing applies for the plastic branch after the yielding. The plastic branch of the analyses coincides with the plastic branch from the tensile tests.

4. Yielding takes place almost at the same load both for the tests and the analyses for all test specimens.

5. There is only one exception concerning test specimen L-20 (Figure 6). The plastic branch for this specimen is almost the same both for the experiment and the relevant analysis. There is a noticeable deviation for the elastic branch of the diagrams. This can be explained probably due to a slip that might have taken place during the onset of the application of the tensile load for this specimen. Probably, an initial slip and a relevant error to the measured elongation might have led to an experimental elastic branch with smaller inclination.

6. The effective length of the test specimens is the one which has been modelled only since this is the length in which the tensile elongation appears (Figure 1). The effective length is equal to $640 \mathrm{~mm}$ (Figure 1).

\section{CONCLUSIONS}

The results stemed from the tensile experiments and the relevant analytical procedures concerning the behavior of the boundary edges of seismic walls under the tensile stage of load application has led to the following conclusions:

1. There is an almost excellent correlation between the experimental results and the analytical results concerning the tensile loading. The analysis has taken place using 3D finite elements.

2. The elastic branch, the yielding point and the plastic branch coincide almost perfectly for almost all specimens except one where the deviation noticed for the elastic branch only can be attributed probably to slip effects and thus, to deviations concerning the measuring of the elongation.

3. The degree of elongation is a very crucial mechanical parameter that affects tremendously the behavior of the boundary edges of structural walls and its investigation has to be applied in the proper and right way following a correct procedure. The convergence between the experimental and the numerical results proves that the procedure applied, probably, follows the right path.

4. A future research could and should model the whole test specimen and not only the effective length in order to simulate even more precisely the experimental behavior. 


\section{REFERENCES}

[1] N. Alamanis, "Influence of random soil strength properties on the earthquake vulnerability of slopes with embedded oil and natural gas pipelines," Energy Systems, 2020, doi: 10.1007/s12667-020-00394-9.

[2] N. Alamanis and P. Dakoulas, "Investigation on the effect of spatial variability of soil properties on permanent seismic displacements of slopes in load," in 14th Baltic Sea Geotechnical Conference 2020, 2020.

[3] N. Alamanis and P. Dakoulas, "Effect of spatial variability of soil properties on the stability and permanent seismic displacements of highway slopes," in The 17th European Conference on Soil Mechanics and Geotechnical Engineering, 2019.

[4] N. Alamanis and P. Dakoulas, "Effect of the spatial variability of soil properties on the seismic vulnerability of slopes with embedded oil and natural gas pipelines," in 6 th International Conference on "Energy, Sustainability and Climate Change" (ESCC 2019), 2019.

[5] N. Alamanis and P. Dakoulas, "Vulnerability of soil slopes against seismic damage based on the effect of spatial variability of soil properties on the development of permanent seismic displacements," in International Conference on Research in Engineering, Technology and Science, 2019.

[6] A. Mouratidis, C. Daniilidou, and G. Papageorgiou, "Evaluation of pavement maintenance and strengthening techniques," in Bituminous Mixtures and Pavements VII, Proceedings of the 7th International Conference on Bituminous Mixtures and Pavements (ICONFBMP 2019), 2019, pp. 516-523.

[7] N. Alamanis, G. Papageorgiou, P. Chantzopoulou, and I. Chouliaras, "Investigation on the influence of permeability coefficient $\mathrm{k}$ of the soil mass on construction settlements. Cases of infrastructure settlements in Greece," Wseas Transactions on Environment and Development, vol. 15, pp. 95-105, 2019.

[8] G. Papageorgiou, N. Alamanis, I. Chouliaras, and P. Kapsali, "Decision making for designing infrastructure projects: The case of the city of Larissa, Greece," Journal of Engineering and Architecture, vol. 7, no. 1, pp. 115-125, 2019, doi:

10.15640/jea.v7n1a13.

[9] G. Papageorgiou and A. Mouratidis, "Defining threshold values for pavement surface characteristics," Proceedings of the Institution of Civil Engineers (ICE) - Transport, vol. 168, no. 3, pp. 223-230, 2015, doi: 10.1680/tran.12.00028.

[10] G. Papageorgiou and A. Mouratidis, "A mathematical approach to define threshold values of pavement characteristics," Structure and Infrastructure Engineering, vol. 10, no. 5, pp. 568-576, 2014.

[11] K. Christidis and K. Trezos, "Experimental investigation of existing non-conforming RC shear walls," Engineering Structures, vol. 140, no., pp. 26-38, 2017, doi: https://doi.org/10.1016/j.engstruct.2017.02.063.

[12] T. Terzioglu, K. Orakcal, and L. M. Massone, "Cyclic lateral load behavior of squat reinforced concrete walls," Engineering Structures, vol. 160, 2018, doi: 10.1016/j.engstruct.2018.01.024.

[13] J. W. Wallace, "Performance-Based Design of Tall Reinforced Concrete Core Wall 
Buildings," Geotechnical, Geological and Earthquake Engineering, vol. 17, pp. 279307, 2010, doi: 10.1007/978-90-481-9544-2_12.

[14] R. Serrette and D. P. Nolan, "Reversed Cyclic Performance of Shear Walls with Wood Panels Attached to Cold-Formed Steel with Pins," Journal of Structural Engineering, vol. 135, no. 8, pp. 959-967, 2009, doi: 10.1061/(asce)st.1943-541x.0000037.

[15] H. S. Lee and D. W. Ko, "Seismic response characteristics of high-rise RC wall buildings having different irregularities in lower stories," Engineering Structures, vol. 29, no. 11, pp. 3149-3167, 2007, doi: 10.1016/j.engstruct.2007.02.014.

[16] X. Lu and Y. Chen, "Modeling of Coupled Shear Walls and Its Experimental Verification," Journal of Structural Engineering, vol. 131, no. 1, pp. 75-84, 2004, doi: 10.1061/(asce)0733-9445(2005)131:1(75).

[17] M. Hassan and S. El-Tawil, "Inelastic dynamic behavior of hybrid coupled walls," ASCE Journal of Structural Engineering, vol. 130, no. 2, pp. 285-296, 2004, doi: $10.1061 / 40616(281) 83$.

[18] L. M. Massone and J. W. Wallace, "Load-Deformation Responses of Slender Reinforced Concrete Walls," ACI Structural Journal, vol. 101, no. 1, pp. 103-113, 2004.

[19] P. Riva, A. Meda, and E. Giuriani, "Cyclic behaviour of a full scale RC structural wall," Engineering Structures, vol. 25, no. 6, pp. 835-845, 2003, doi: 10.1016/S01410296(03)00020-8.

[20] A. Rutenberg, "The seismic shear of ductile cantilever wall systems in multistorey structures," Earthquake Engineering and Structural Dynamics, vol. 33, no. 7, pp. 881896, 2004, doi: 10.1002/eqe.384.

[21] Y. Chiou, Y. Mo, F. Hsiao, Y. Liou, and M. Sheu, "Experimental and analytical studies on large-scale reinforced concrete framed shear walls," Symposium Paper, vol. 211, no., pp. 201-222, 2003.

[22] T. A. Duffey, C. R. Farrar, and A. Goldman, "Low-Rise Shear Wall Ultimate Drift Limits," Earthquake Spectra, vol. 10, no. 4. pp. 655-674, 2003, doi: 10.1193/1.1585792.

[23] Y. L. Mo, J. Zhong, and T. T. C. Hsu, "Seismic simulation of RC wall-type structures," Engineering Structures, vol. 30, no. 11, pp. 3167-3175, 2008, doi:

10.1016/j.engstruct.2008.04.033.

[24] I. Ghorbani-Renani, N. Velev, R. Tremblay, D. Palermo, B. Massicotte, and P. Léger, "Modeling and testing influence of scaling effects on inelastic response of shear walls," ACI Structural Journal, vol. 106, no. 3, pp. 358-367, 2009.

[25] J. D. Aristizabal-Ocfaoa, "Seismic Behavior of Slender Coupled Wall Systems," Journal of Structural Engineering, vol. 113, no. 10, pp. 2221-2234, 2008, doi: 10.1061/(asce)0733-9445(1987)113:10(2221).

[26] P. Bisch and A. Coin, "Seismic behaviour of slightly reinforced concrete walls: Experiments and theoretical conclusions," Bulletin of Earthquake Engineering, vol. 5, no. 1, pp. 45-65, 2007, doi: 10.1007/s10518-006-9014-1.

[27] T. Chrysanidis, "Evaluation of Out-of-Plane Response of R/C Structural Wall Boundary Edges Detailed with Maximum Code-Prescribed Longitudinal 
Reinforcement Ratio," International Journal of Concrete Structures and Materials, vol. 14, no. 1. 2020, doi: 10.1186/s40069-019-0378-4.

[28] T. Chrysanidis, "Influence of elongation degree on transverse buckling of confined boundary regions of R/C seismic walls," Construction and Building Materials, vol. 211, pp. 703-720, Jun. 2019, doi: 10.1016/J.CONBUILDMAT.2019.03.271.

[29] T. Chrysanidis and I. Tegos, "Does reinforcement ratio affect displacements due to lateral buckling behavior of concrete walls?," International Journal of Applied Engineering Research, vol. 12, no. 3, pp. 382-388, 2017.

[30] T. Chrysanidis and I. Tegos, "Influence of elongation degree on out-of-plane buckling of R/C structural walls with a medium high reinforcement ratio," International Journal of Civil Engineering and Technology, vol. 7, no. 4, pp. 358-364, 2016.

[31] T. Chrysanidis and I. Tegos, "Size of seismic tensile strain and its influence on the displacements due to transverse buckling of ultra-highly reinforced structural walls," ARPN Journal of Engineering and Applied Sciences, vol. 11, no. 23, pp. 13884-13890, 2016.

[32] T. Chrysanidis and I. Tegos, "Displacements and mode of failure of medium high reinforced walls due to transverse buckling," International Journal of Engineering Development and Research, vol. 4, no. 3, pp. 628-634, 2016.

[33] T. Chrysanidis, "Low Reinforced Shear Walls: Displacements and Failure Modes Due to Lateral Buckling," International Journal of Science and Engineering Investigations, vol. 5, no. 55, pp. 143-148, 2016.

[34] T. Chrysanidis, "Degree of Elongation of Maximum Code-Prescribed Reinforced Walls: Modes of Failure and Displacements of Lateral Buckling Phenomenon," International Journal of Trend in Research and Development, vol. 3, no. 4, pp. 435440, 2016.

[35] T. Chrysanidis, "Size of seismic tensile strain and its influence on the lateral buckling of highly reinforced concrete walls," IOSR Journal of Mechanical and Civil Engineering, vol. 11, no. 1, pp. 18-22, 2014, doi: 10.9790/1684-11121822.

[36] T. Chrysanidis and I. Tegos, "Out-of-plane buckling of highly reinforced seismic walls: Displacements and mode of failure," International Journal of Civil Engineering and Technology, vol. 5, no. 6, pp. 101-107, 2014.

[37] C. Alarcon, M. Hube, R. Jünemann, and J. de la Llera, "Characteristics and displacement capacity of reinforced concrete walls in damaged buildings during 2010 Chile earthquake," Bulletin of Earthquake Engineering, vol. 13, pp. 1119-1139, 2015, doi: https://doi.org/10.1007/s10518-015-9727-0.

[38] A. Haro, M. Kowalsky, Y. Chai, and G. Lucier, "Boundary elements of special reinforced concrete walls tested under different loading paths," Earthquake Spectra, vol. 34, no. 3, pp. 1267-1288, 2018, doi: 10.1193/081617EQS160M.

[39] K. Herrick and M. Kowalsky, "Out-of-plane buckling of ductile reinforced structural walls due to in-plane loads," Journal of Structural Engineering, vol. 143, no. 3, pp. 115, 2016, doi: 10.1061/(asce)st.1943-541x.0001660.

[40] Y. Chai and S. Kunnath, "Minimum thickness for ductile RC structural walls," Engineering Structures, vol. 27, no. 7, pp. 1052-1063, Jun. 2005, doi: 
10.1016/j.engstruct.2005.02.004.

[41] T. Welt, L. Massone, J. LaFave, D. Lehman, S. McCabe, and P. Polanco, "Confinement behavior of rectangular RC prisms simulating wall boundary elements," Journal of Structural Engineering, vol. 143, no. 4, pp. 1-12, 2017, doi: 10.1061/(asce)st.1943-541x.0001682.

[42] T. Chrysanidis and V. Panoskaltsis, "Does the degree of tensile strain have an impact on the cracking behavior of vertical structural elements?," in IOP Conference Series: Materials Science and Engineering, 2020 5th International Conference on Civil Engineering and Materials Science (ICCEMS 2020), 2020, vol. 897, doi: 10.1088/1757-899X/897/1/012004.

[43] T. Chrysanidis and V. Panoskaltsis, "Evaluation of cracking behavior of R/C vertical components reinforced with varying longitudinal reinforcement ratios," in Proceedings of the XI International Conference on Structural Dynamics (EURODYN 2020), 2020, pp. 3186-3197, doi: 10.47964/1120.9260.18887.

[44] T. Chrysanidis and V. Panoskaltsis, "Experimental investigation of the influence of tensile strain on the cracking of R/C vertical structural elements," in Proceedings of the XI International Conference on Structural Dynamics (EURODYN 2020), 2020, pp. 3174-3185, doi: 10.47964/1120.9259.18582.

[45] T. Chrysanidis and I. Tegos, "Influence of elongation degree on the behavior of R/C structural walls with maximum code-prescribed reinforcement ratio," in Proceedings of the 170th International Conference on Civil and Environmental Engineering (ICCEE 2017), 2017, pp. 8-12.

[46] T. Chrysanidis and I. Tegos, "How does degree of elongation affect lateral buckling behavior of seismic walls?," American Academic and Scholarly Research Journal, vol. 7, no. 4, pp. 266-272, 2015.

[47] T. Chrysanidis and I. Tegos, "The influence of the degree of elongation to the displacements of structural walls with low-reinforced end-sections," American Academic and Scholarly Research Journal, vol. 7, no. 4, pp. 259-265, 2015.

[48] T. Chrysanidis and I. Tegos, "The influence of the degree of elongation to the displacements of seismic walls with maximum code-prescribed reinforcement ratio," American Academic and Scholarly Research Journal, vol. 7, no. 4, pp. 273-279, 2015.

[49] T. Chrysanidis, "The influence of the degree of tensile strain to the ultimate strength and mode of failure of seismic walls with low-reinforced end-sections," American Academic and Scholarly Research Journal, vol. 6, no. 4, pp. 337-343, 2014.

[50] T. Chrysanidis, "The influence of tensile strain of the high-reinforced end sections of seismic walls to their displacements and mode of failure," in Proceedings of the International Conference on Recent Trends in Engineering and Technology - 2014 (IJBRMM's ICRTET 2014 ), 2014.

[51] T. Chrysanidis and I. Tegos, "Does degree of elongation affect displacements of structural walls?," American Academic and Scholarly Research Journal, vol. 6, no. 4, pp. 344-350, 2014. 